\title{
Pluralism in qualitative research: the impact of different researchers and qualitative approaches on the analysis of qualitative data
}

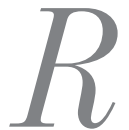

Qualitative Research Copyright (C) 2010 The Author(s) http://qrj.sagepub.com vol. 10(4) 441-460

\author{
NOLLAIG FROST AND SEVASTI MELISSA NOLAS \\ Middlesex University, UK \\ BELINDA BROOKS-GORDON \\ Birkbeck, University of London, UK \\ CIGDEM ESIN \\ University of East London, UK \\ AMANDA HOLT \\ University of Portsmouth, UK \\ LEILA MEHDIZADEH \\ University of Leeds, UK \\ PNINA SHINEBOURNE \\ Birkbeck, University of London, UK
}

ABSTRACT Qualitative approaches to research in psychology and the social sciences are increasingly used. The variety of approaches incorporates different epistemologies, theoretical traditions and practices with associated analysis techniques spanning a range of theoretical and empirical frameworks. Despite the increase in mixed method approaches it is unusual for qualitative methods to be used in combination with each other. The Pluralism in Qualitative Research project (PQR) was developed in order to investigate the benefits and creative tensions of integrating diverse qualitative approaches. Among other objectives it seeks to interrogate the contributions and impact of researchers and methods on data analysis. The article presents our pluralistic analysis of a single semi-structured interview transcript. Analyses were carried out by different researchers using grounded theory, Foucauldian discourse analysis, interpretative phenomenological analysis and narrative analysis. We discuss the variation and agreement in the analysis of the data. The implications of the findings on the conduct, writing and presentation of qualitative research are discussed.

KEYWORDS: mixed methods, pluralism, qualitative research, rigour, subjectivity, transparency 


\section{Introduction}

Qualitative researchers aim to capture the meanings of narratives along several dimensions, including the argumentative, discursive, emotional, sentient, imaginary, spiritual, temporal and spatial (Mason, 2006). Given the burgeoning interest in furthering understanding of data and phenomena by whatever means available, and the great number of qualitative methods, techniques and practices now available (e.g. Denzin and Lincoln, 2000; Easterby-Smith et al., 2008; Willig and Stainton-Rogers, 2008) researchers are starting to explore the combining of qualitative approaches with each other (e.g. Moran-Ellis et al., 2006). The use of more than one qualitative approach with another is what is meant in this article by pluralism in qualitative research.

This article builds on the first author's previous work (Frost, 2006, 2009) on exploring the use of within-method pluralistic approaches to qualitative research. We present findings from a study that was developed to explore acrossmethod pluralistic approaches to qualitative research, the Pluralism in Qualitative Research (PQR) study. The study employed four data analysts to use one of four widely used qualitative analysis techniques to analyse one semistructured interview transcript. The four qualitative analysis methods employed were grounded theory (GT), interpretative phenomenological analysis (IPA), Foucauldian discourse analysis (FDA) and narrative analysis (NA). These were chosen because they reflect four of the more commonly used approaches to qualitative research in the social sciences and are the particular areas of analysis specialized in at several of the institutions from which the research assistants were recruited. One purpose of our study was to explore what meanings could be made from the same data analysed by four different people using four different analytical lenses. To examine this in detail we also studied the researcher impact on the data analysis and our findings in this area are presented in this article.

Before introducing the study in more detail we develop the concept of pluralism in qualitative research and briefly outline the four approaches that were used in the study.

\section{Pluralism in qualitative research}

Qualitative research encompasses a wide range of approaches and also encompasses the mixing of those approaches (e.g. Dicks et al., 2006; Moran-Ellis et al., 2006). There is a range of advice about which methods to use when. Eclecticism, for instance, regards all possible methods as equal and advocates the use of the ones most suitable for the research at hand (Todd et al., 2004). Bricolage and 'pragmatic' approaches (Denzin and Lincoln, 2000; Kincheloe, 2001; Onwuegbuzie and Leech, 2005) suggest combining methodological ontologies in the pursuit of a more extensive understanding of the needs of human beings (Howard, 1983).

Given the variety of techniques and epistemological origins within qualitative techniques, the use of a single qualitative approach to access meaning in data 
raises questions about what the use of another method would have illuminated in the data. Employing pluralistic approaches to explore how different researchers make sense of the data provides different ways of understanding how meaning in data is reached. Considered together, the layers of interpretation can provide an array of perspectives of participants' accounts of their experiences. Considered separately, different interpretations of data can provide views from different dimensions from which the one(s) of most relevance to the researcher can be extracted.

Seeking to understand the contributions made by researchers and methods to the transformation of data when working pluralistically enables a heightened transparency to be brought to the analysis process. This transparency is potentially of relevance to clinicians, policy- makers and commercial researchers who seek to bring 'trustworthy evidence' developed from robust research to practical applications.

One argument concerning the mixing of qualitative and quantitative methods is that not to do so at the very least raises questions about whether researchers are accessing all that is available to them in the data (Bryman, 2007). We apply this argument to questions of research that seek to access holistic and multi-perspective insight to individual and social experience in a pluralistic qualitative approach.

In order to orient the reader to the discussion that follows we present a brief outline of the ways in which each of the four qualitative methods were employed in this study.

\section{GROUNDED THEORY}

Since its conception in the 1960s (Glaser and Strauss, 1965, 1967) the grounded theory approach has developed as a set of differently situated inquiry methods (Charmaz and Henwood, 2008). All the methods provide 'flexible, successive analytic strategies for constructing inductive theories from the data' (Charmaz and Henwood, 2008: 240).

Grounded theory is used by researchers to generate theories that account for patterns of behaviour and social processes that are both 'relevant and problematic for the actors involved' (Strauss, 1987: 34). It is influenced by experimental thinking in social psychology (Glaser, 1978), as well as symbolic interactionist thought in microsociology (e.g. Clarke, 2003, 2005). It is grounded in deriving theory that is faithful to the everyday reality of the phenomenon under investigation.

Grounded theory is based on a 'general method of comparative analysis' (Glaser and Strauss, 1967: 1). It works by identifying concepts in the data (happenings, events, and other instances of phenomena) which are then extensively compared and contrasted with other concepts. Similarities are grouped together with the most abstract grouping forming a category. Concepts and categories are continuously tested against new data instances until theoretical saturation has been reached and the resultant categories 'fit' the data. Glaser and Strauss suggest that there are two types of categories, those defined by researchers and those defined by research participants.

Many of the observations that are analysed are made from a particular perspective (that of the researcher) (Willig, 2001). In grounded theory it is assumed 
that data are 'raw' and unmediated and that it is possible to reflect the actor's points of views.

\section{FOUCAULDIAN DISCOURSE ANALYSIS}

Foucauldian discourse analysis (FDA) is a methodology derived from poststructuralism and, in particular, from Foucault's conceptions of power relations and subjectivity. Taking a social constructionist framework, Foucauldian discourse analysis aims to examine how 'objects' and 'subjects' are constructed in discourse and to explore what the effects of this might be - effects which might be 'real' in the sense that they are experienced as real. For example, discourse, which includes institutional and social practices, offers up (and closes down) particular subject positions, that is, possible social locations which afford or delimit the particular experiences or 'ways of being'.

Many discourse analysts have outlined series of 'steps' (e.g. Parker, 1992; Willig, 2008) and 'worked examples' (e.g. Gill, 2000; Wood and Kroger, 2000) to structure this analytic process. This usually includes stages such as the identification of discursive constructions, the identification of these within wider discourses, the identification of 'subject positions' made available within these discourse and the mapping of possibilities for action and subjective experiences (Willig, 2008). However, perhaps what is more useful is Walton's (2007) observation that discourse analysis is less to do with following prescribed steps and more about conducting analysis in the spirit of post-structuralist enquiry: that is, to avoid making 'truth-claims', to utilise appropriate analytic concepts and to report findings in a way which is consistent with the appropriate theoretical and epistemological positions

Reflexivity is key to this methodological approach, since the approach itself recognizes that knowledge claims are 'ideological, political and permeated with values' (Schwandt, 2000: 198) and it therefore involves the acknowledgement that the researcher's interpretation is a privileged one which silences possible others, the implications of which require consideration. Furthermore, such epistemological foundations clearly impact on the way such an analysis can be evaluated. Thus, Stenner (1993) suggests that discourse analysis produces a reading, rather than an interpretation, as there is no supposition of an 'outside truth' against which the analysis can be assessed. Thus, judgement of its quality must be in terms of its usefulness, rather than accuracy.

\section{NARRATIVE ANALYSIS}

Narrative analysis is based on the premise that people use stories to make sense of themselves and their world and to present themselves to others (Sarbin, 1986). It is often at times of change or incoherence in their lives that stories are particularly useful to individuals to understand changes in their identities and their relationships (e.g. Bruner, 1987; Emerson and Frosh, 2004; Riessman, 1993, 2008). Narrative analysts explore data for stories and examine them for 
content, form and function (Halliday, 1973). Narrative analysis deals with how the narrator, the leading character of the told story, makes interpretations. The aim is to understand the ways in which a story works in a certain context; the mechanisms by which it is consumed; and how stories are silenced, contested or accepted (Riessman, 1993, 2008). It is thus especially useful in the study of formation, reformulation and maintenance of identity since this approach gives prominence to human agency and imagination. As with other qualitative approaches different methods of narrative analysis enquiry have developed as researchers from different positions seek different employment of narrative analysis.

Early models of narrative analysis (Labov, 1972; Labov and Waletzky, 1967) used traditional story structure to identify the 'beginning, middle and end' of narratives contained in accounts. The models propose that stories which capture the attention of an audience generally contain all of these elements and can be identified by a temporal ordering of events. The models are widely regarded as providing the starting point for the 'narrative turn' that has led to the acceptance of narrative analysis as a research method across the social sciences (Riessman, 2008). The models led to changes that included the way in which the research interview is perceived and used (Mishler, 1986), the identification of story genres (Polkinghorne, 1988) and a focus on linguistic features of narratives (Gee, 1991). The inclusion of the subjectivity of the interviewer as well as of the participant in narrative analysis has led to the development of critical approaches (e.g. Emerson and Frosh, 2004) and many diverse forms arising from the diversity of investigators' theoretical and epistemological frameworks. Narrative analysis is now extensively used across disciplines from research areas that seek to gain insight to the diversity of women's experiences (e.g. Sands, 2004) to those that study education (e.g. Cortazzi, 2002[1993]) and medicine (e.g. Hurwitz et al., 2004; Hydén and Brockmeier, 2008; Riessman, 2003).

\section{INTERPRETATIVE PHENOMENOLOGICAL ANALYSIS}

Interpretative phenomenological analysis is concerned with a detailed examination of individual lived experience and how individuals are making sense of that experience. It is influenced by hermeneutics and theories of interpretation (Eatough and Smith, 2008). It is phenomenological in its detailed examination of personal lived experience of participants and in exploring how participants make sense of their experience (Smith, 2004). It is interpretative in recognizing the role of the researcher in making sense of the experience of participants.

IPA works with a double hermeneutic orientated towards empathy and critique (Smith, 2004: 46) and provides the researcher with a framework and a process for data analysis consistent with its theoretical underpinnings. At the same time the process of analysis remains flexible and open to adaptation.

In terms of complementarities and contradictions with the other approaches used in the study, IPA has affinities with grounded theory and discursive 
psychology. IPA is also informed by the theoretical perspective of symbolic interactionism (Smith, 1996) which is concerned with how meanings are constructed by individuals within both a social and personal world. Thus, 'IPA endorses social constructionism's claim that sociocultural and historical processes are central to how we experience and understand our lives, including the stories we tell about these lives' (Eatough and Smith, 2008: 184). In this respect IPA shares some commonalities with the roots of grounded theory.

\section{The pluralism in qualitative research project ( $P Q R$ )}

In order to begin to explore questions about what meanings can be made from data, the Pluralism in Qualitative Research (PQR) project was developed. This project applied four different qualitative analysis techniques to the transcript of one semi-structured interview to identify and explore creative tensions that result from a pluralistic qualitative approach and to investigate the interpretations made by each approach. The analyses were carried out by four research assistants (RAs), each using one method. The RAs were interviewed individually about their experience of the research process on completion of the work. In this article we draw on those interviews and on the field journals kept during the analysis process by the RAs to study the ways in which they write and talk about the analysis process. This provides us with insight to the struggles and conflicts with the use of their method and positioning of themselves that they confront as qualitative researchers. Some of the struggles are explicitly described by the RAs while others are implicit in their descriptions. Foregrounding the RA and method impact on the analysis process across four different techniques provides a starting point to understanding ways in which pluralistic qualitative approaches may contribute to enhancing transparency and trustworthiness in qualitative research.

\section{Research methods}

The data for this article derive from data analyses carried out by Research Assistants using grounded theory (GT), interpretative phenomenological analysis (IPA), Foucauldian discourse analysis (FDA) and narrative analysis (NA) to analyse an interview transcript of one woman's account of her transition to second-time motherhood. The interview had been carried out by the first author as part of a larger study that explored women's experiences of becoming a mother of two children (Frost, 2006). It was transcribed and sent to the RAs by email and in hard copy. Each RA was interviewed by another member of the PQR team about the analysis they had carried out. Data was also derived from the field journals that each RA kept during the time they were performing the analysis. 
The RAs were recruited from academic institutions across the UK. They were all $\mathrm{PhD}$ students using a particular qualitative approach. Their areas of doctoral study covered female embodiment, parenting and youth justice, addiction and recovery, and clinical decision-making. Each RA was sent the interview transcript with a request to analyse it by their identified method and return the analysis by a specified date. When all four analyses were complete semi-structured interviews were carried out with each RA. The interviews probed the RAs descriptions of, views on and practices in their use of the method as well as their experience of the research process. Each interview lasted approximately 45 minutes. Each interview was transcribed by one of the $\mathrm{PQR}$ project co-ordinators and analysed collectively by all three co-ordinators. The analysis looked for themes using cross- comparative analysis and themes were grouped into categories relating to data, method and process.

During the interviews the RAs were asked how they used the method. Their response to this provides the main source of reflection on the impact of method in this article. In addition, sometimes the RAs addressed this topic before the question was asked and sometimes referred to it across the course of the interview. RAs were also asked about their views of the way the research had been designed and what it was like to be part of it. These questions were designed to bring out RAs' views about how they had impacted or influenced the way the findings had been made. The RAs talked about how they thought their presence formed part of the process and outlined their struggles with objective and subjective stances. Their responses indicated that they were not always aware of their impact and how this was conveyed in the write-up of the findings in the data.

All the RAs expressed their concern about not knowing where in the writeup to include descriptions of their impact on the interpretations. They described not knowing how much of their role to include in the write-up and of having to make active choices about use of the first person and in identifying assumptions they had brought to the interpretations. Although all the RAs did reach decisions and portrayed their choice in the written analyses they described feeling anxious throughout the analysis process and during the interview about how they chose to do this.

In addition to analysis of the interview transcripts obtained from the RAs the PQR co-ordinators examined the field journals the RAs kept while conducting the analysis. These were cross-compared individually with each RA's data analysis and interview transcript. The field journals differed in style across each RA. All had the choice as to whether to submit their journal to the project team for study. The aim of studying the journals was to give richer understanding of the way in which the RAs spoke about and presented their perceived personal and methodological impact on the analytic process.

Given the confidential nature of some of the field journals we have tried to prevent identification of method with RA in this article by assigning pseudonyms to each RA. 
Table of Participants

\begin{tabular}{ll}
\hline Role in PQR Team & Name/Pseudonym \\
\hline Narrator & Karen \\
Project Co-ordinator & Nollaig Frost (NF) \\
Project Co-ordinator & Belinda Brooks-Gordon (BBG) \\
Project Co-ordinator & Sevasti-Melissa Nolas (SMN) \\
Research Assistant & Gabby \\
Research Assistant & Nancy \\
Research Assistant & Ada \\
Research Assistant & Slavonica \\
Administrator & Polona Curk \\
\hline
\end{tabular}

\section{Findings}

DESCRIPTIONS OF USE OF CHOSEN QUALITATIVE APPROACH

In the course of exploring the data we noticed a tendency for RAs to describe aspects of the interview transcript that could not be investigated using their chosen technique of analysis. They suggested alternative methods to supplement or enhance the analysis they had carried out. At the start of her written analysis Nancy uses her field journal to describe a possible alternative approach:

I am not sure what I will do with this, as I wonder whether a more poetic narrative analysis could do a lot of powerful stuff with it.

Later in the analyses she describes a second possible method:

A more psychoanalytical approach might usefully explain this discrepancy, possibly as an example of projection.

When discussing her method in her interview Nancy supports her choice of method and describes how she became more confident with it as the process progressed:

As the process went through I found it a lot easier than I thought I would and I got a handle on it quite quickly and how I wanted to work with it and by the end when I had kind of read it and I had written a draft I actually felt quite pleased with it.

Ada also includes discussion of a possible alternative approach in her written analysis but then dismisses it as beyond the scope of her involvement in the project:

The second alternative is beyond the scope of this project as this would involve a detailed engagement with the relevant literature and would depend on the particular focus of the research as a whole.

The question of whether to cite references in the written presentation of the findings was also raised by Nancy. She decides that she will include references and writes about this in her journal. She seems to be unsure as to what is expected but unwilling to risk lowering the quality of the work by leaving them 
out completely. Her compromise, of 'including just a few references' causes the process to be extended and she seems unsure whether it has brought it to sufficient standard:

Decided to hedge my bets and include just a few references. This part is taking longer than I thought - especially finding the refs - and I am eager to complete now but I keep reading through it and thinking that it could be better.

It could be that the confusion about whether to improve literary references arose from the minimal nature of the instructions provided. These quotes however also illustrate a concern to submit work of a high standard and an uncertainty about what constitutes this, in the context of this project.

As with Nancy, Ada is also enthusiastic in her interview about the approach that she does select:

Now it evolves into something which opens up the phenomenological account, lovely phenomenological account into more abstract and critical understanding, examining what's happening here and relating it to now depends where you frame this.

but unlike Nancy, she also highlights in her verbal account the aspects of the text that she cannot investigate using this method:

There is something here that I put aside. I am not analysing it but it can't actually be pushed away. I mean there is another dimension here. For another time I can do a complete literary analysis looking at the images and the metaphors.

For one RA, Slavonica, there was an expectation that she could not introduce her assumptions in the presentation of the findings. In her interview she describes checking her work to locate any assumptions that may have been included and the conflict between adopting an objective and subjective stance in all qualitative work she undertakes:

Well I've been looking though it all over again and looking at the places where I may have brought in my own assumptions and I think that's what I always find a challenge, to try and maintain as much objectivity as possible because sometimes you feel as though you know what they are talking about and you know what they're implying but it is so hard you know not to finish people's sentences or let them know you think you know what they are talking about and it might not be that.

Gabby described a similar confusion about striving to be objective in this analysis:

Of course this is not an objective analysis or something like that. I'm doing the analysis and everything about me directly influences my analysis and not only my academic background as a woman as an individual woman how I see life and how I approach motherhood and so I try to be fair and objective as far as I can but I can't, we all do know that it is the downside of being an analyst.

Nancy sums up this confusion about whether and how to include the personal by writing in her journal:

Occasionally an 'I' would creep into the text but it felt inconsistent so I self-consciously removed it. 


\section{DESCRIPTIONS OF THE NARRATOR AND HER ACCOUNT}

Qualitative researchers often describe the evolution of relationships between themselves and the data and its narrator through the process of analysis. In this study we found that the RAs described relationships formed with the narrator and with the research artefacts. We were particularly interested to explore these relationships given that none of the RAs had met the narrator or carried out the interview with her. The type of relationships formed appeared to differ across the methods and RAs. Gabby described in her interview how she felt about the narrator and the personal relationships formed in the analysis process:

I liked her very much personally. Of course you develop a relationship, personal relationship whilst doing the analysis because it's just natural you know.

A discursively-orientated RA used her journal to describe similarities and differences between herself and the narrator, perhaps also in efforts to personalize her:

It also struck me that I was the same age as the narrator. I do not have children and I wondered how this was affecting my reading.

Other RAs used less personalized language to refer to the narrator and to describe her account and we wondered how the words they used to write about the analysis show their beliefs and attitudes to the experiences the narrator was recounting. Contrasts between two written analyses illustrate this. Slavonica frequently described the narrator's descriptions of her experience of motherhood as 'dramatic'.

'... we can see that she was anticipating a dramatic impact even before the arrival of her first child:

'she expresses her feelings quite dramatically'

'This is quite a dramatic anticipation and may have something to do with a book that she had been reading that supposedly presents the worst case scenarios of raising children.'

'So it is difficult to determine whether she is expecting the emotional impact of a second child to be just as dramatic, or less so than the first child.'

By contrast, Gabby portrayed in her written analysis of the interview transcript her view of the account of the narrator's experiences as a nuanced experience full of tensions and contradictions and one in which the narrator strived towards some sort of balance:

The interview is constructed on the multiple positions of the mother within and beyond the modern discourses of motherhood. From the beginning of the interview, she tells us the tensions and contradictions she has been experiencing in being a 'good enough mother' as well as her attempt to find a balance between her professional life and motherhood. Her narrative is shaped by her travel between her positions representing various storylines surrounding motherhood.

Gabby approaches the narrator's account not as an extraordinary, dramatic event but with the assumption that motherhood is riddled with "emotional 
ambiguity'. Such 'ambiguity' is accepted and explored as normal through her analysis. Neither Slavonica nor Gabby were mothers and so their views of the narrator's accounts were not influenced by personal experience of motherhood.

\section{CONTEXT}

All the RAs commented on their initial wariness of conducting analysis on the transcript of an interview that they had not conducted. For one RA the missing interaction between interviewer and interviewee was a concern that she was subsequently able to dissipate:

And the other thing I want to say right at the beginning is that I obviously did not interview that person and maybe it's a bit different because it's one step removed and what I have is a text and what is missing is the intonation the accent the person is in the room and what is the interaction with me and what kind of gestures and pauses and so on. In a way what the texture is. So initially it felt more removed than similar things that I did on the basis of having interviewed the person but then I just switched perspective inside and I thought well ok it's a different experience go with it. (Ada)

Later in her interview Ada raised a question about the relevance of researcherconducted interviews and suggested that to focus on a text alone allows a freshness of perspective not present when the researcher has also sought out and recruited participants:

In a way we are all so intent on finding people to interview and we want to get a raw experience of what people are telling us and sometimes for the first time you know but to what extent is it relevant and enriching also to look at texts which have already been written.

Nancy appears to agree, hesitantly, with the view that RA involvement can 'muddy' the data collection:

I suppose I suppose I possibly would have needed to have got more of the context but that didn't happen because I wasn't given that information. I suppose what I would have to be careful of is that although that is my analytical model I would try to avoid looking for it at this stage of getting the data. I think I still would have done very broad questions because what I wouldn't have wanted to do was to start asking questions that would have been tapping in to being regulated and how you negotiate this because then I'm assuming that the interviewee is doing these things and to me that would um that would be kind of pre empting the interview I suppose.

Her focus is on the how her conduct of the interview would have differed and what impositions this would have brought to it. By analysing an interview transcript of an interview that she was not part of, Nancy suggests she is able to avoid pre-empting response the interviewee would make. This demonstrates a similar awareness to that of Slavonica whose earlier quote described her efforts not to 'finish people's sentences or let them know you think you know what they are talking about' 
Nancy also discusses how the data collected would differ with interviewer style:

From what I gathered it was more interviewer directed than the way I would direct an interview so I might have collected different data because I would have just said 'Tell me your experiences' and asked them to start right at the beginning.

Nancy links interview style to the analytical model she employs, whereas Ada's comments refer to the generalized issue of recruiting participants and are not method-specific.

In general, these remarks suggest that these RAs believe that analysis of qualitative data can be carried out on text not gathered by them. The analyses they presented and their discussion about the narrator and her experiences show that in the absence of a physical presence a picture of the narrator is constructed from the text by approaching the interview transcript as a research artefact that is separate from the rest of the research process or, in the example of Nancy, personalizing the narrator by creating comparisons with themselves.

\section{EXCLUSIVITY OF LANGUAGE}

While examining the interview transcripts, field journals and written analyses of the data we were interested to note that the language used sometimes seemed exclusive to the method employed. Those approaches that examine the data for themes used terms such as 'overarching themes' and 'superordinate themes'. It became clear that the overarching theme the interviewee focussed on was the emotional impact of becoming a mother for the first time:

Again you eliminate some, you group them together in maybe a more sensible way and you come up with a final list of themes which I've got on Stage 4 here, Table of Themes, and I group them into kind of super ordinate themes overall and kind of sub divisions.

One effect of this way of presenting the data is to simplify and reduce passages of the transcript. This is illustrated in the following passage in which the narrator's account of the complexities of her relationship with her partner is reduced to a few lines:

Relationships theme: Although the mother values the relationship with her partner who is presented as 'the person you want to spend the rest of your life with and you're happy' (382), she also feels the difference in intensity: 'He of course cares as much about her as I do but it's just a different kind of feeling I think, it's not quite as visceral.

The simplifications sometimes also cause the interpretation of the data to be described as fact and with little indication of the RA's role in the transformation of the data to its final presentation, as illustrated in this quote taken from another written analysis: 
So here we understand her meaning of a 'car crash' to be emotional in nature however the description is still somewhat vague and from the quote 'it is definitely the emotional side that is almost impossible to explain to anyone' we can appreciate why. She finds it difficult to express this experience in words.

The factual treatment of the data and its presentation in objective language is reminiscent of the presentation of the results of more positivist-orientated research. The RA is removed to a position of expertise and it is not clear how the interpretation has been reached.

The RAs whose analyses were discursive and narrative-orientated demonstrated greater ownership of their role in the interpretative process by using the first person in their written analysis. This gave the reader insight to the unfolding of the RA's understanding and awareness of the different levels or spaces/positions between the person speaking, the person asking the question, the material result of that interaction (the transcript) and the analysis process which involves different interactions between the analyst, the text and their memory of the interview event.

In my first reading, I thought that she did not talk about her body except the lines where she described the baby as a part of her body. Later, I realised that she implicitly talks about her body in between the lines where she tells about the tiring routine of looking after a child.

However an implicit adherence to positivist language was also evident in presentations of discursive exploration of the data. The RAs who examined the account for ways in which its topics were talked about, used terms such as 'scientification' and 'discourses' to describe the narrator's account. Use of these terms served to position the RA as a holder of exclusive knowledge and expertise:

In this extract, she refers to the scientification of child-care. This discourse creates mothers who read books, and study child-care so as to standardize this process.

When the RAs described their use of their method in their interviews it was noticeable that both thematic-orientated RAs spoke of 'systematic exploration' of the interview text while the discursive and narrative orientated RAs spoke of 'reading' the text.

The differences in the language used and the presentations of the findings by each RA led the project co-ordinators to speculate on the existence of a relationship between personality and choice of method. We found that those using thematic approaches explicitly linked the approach to their style of thinking:

So I read it and read it as you can see it goes all over the place and that's my way of thinking which is not very linear

There's some kind of structure to it that you can kind of follow and I work in a very structured way so I need that kind of order when I'm doing something. It can all become so messy and you can be overwhelmed with so many words you don't know what to do. 


\section{Discussion}

By paying close attention to the ways in which the RAs in this study presented their analysis and talked about their involvement in it, this article has identified aspects of their impact and of the method they employ in the analysis process. The article has shown that these RAs had awareness of their presence in the transformation of the data. They described the care they took to minimize the introduction of their assumptions into the analysis and their concerns to balance objective or subjective stances. Their accounts also demonstrated aspects of their impact and that of their method of which they were not aware. These included inferences made by the language they used in the written presentation of their analysis and its findings and the associated simplification and reduction of the data. The interviews with the RAs showed that they developed relationships with the narrator and the research artefacts and imply that their perceptions of each influenced their descriptions of the process and its findings.

In this article we have purposely avoided describing the RA impact as 'subjectivity'. The question of understanding individual accounts of experience in qualitative research raises questions about subjectivity and reflexivity. Subjectivity in qualitative research can be taken to mean the living knowledge of an individual, which is drawn upon in the co-construction of the meaning of an experience by researcher and researched (Reason and Riley, 2008; Todd et al., 2004). Reflexivity can be understood to be the psychological meaning-making of the individual (Frosh and Saville Young, 2008). Both terms and concepts are widely used in qualitative research in recognition of its turning away from positivism and of the impossibility of the qualitative approach representing a search for absolute knowledge (Frosh and Saville Young, 2008: 111).

There is a current and lively debate about the constitution and role of subjectivity in research and other areas (e.g. Drapeau, 2002; Frosh, 2005; Venn, 1998; Wetherell, 2008) and it is not the intention of the authors to enter into that debate in this article. Any discussion of subjectivity as a concrete notion is always troubled by the fact that it does not exist as a rigid and bounded entity or process. The common understanding that it is a representation of the individual's interior world makes it at once unknowable to the outsider and at the same time, known only in parts to its owner (Frosh and Saville Young, 2008; Todd et al., 2004; Wetherell, 2008). Add to this the fact that when research is described for an audience, the researcher's awareness will control what they can of the subjectivity they want to make public. It also raises the question of how much of their subjectivity is transparent to the individual. Instead, in this article we have sought to bring to life some of the implicit and explicit understandings and assumptions about the impact of the personal in qualitative research by highlighting the ways in which individual RAs describe it. 
Some of the ways that have been highlighted include the RAs accounts of their creation of interview context and narrator demographics in the absence of physical presence, differences in written and spoken descriptions of the strengths and limitations of the approach employed and the influences of the RAs' personal biographies in their choice of method. These have been illuminated through close study of a variety of research artefacts and the relationships formed with them.

A key issue to consider in the use and combination of qualitative approaches is whether the qualitative research paradigm has a place to illustrate how researcher expectations and assumptions are understood, applied and presented. Moves towards making the researcher's role transparent in the transformation of data are evolving. For example, the subjective element in the data transformation process is made clear in IPA research where differing levels of interpretation ranging from the 'empathic-descriptive' to the 'criticalhermeneutic' have been identified (Eatough and Smith, 2008). This range of levels reflects the tensions between descriptive and interpretative approaches identified by Ricoeur's distinction between a hermeneutics of faith (empathic interpretation) and a hermeneutics of suspicion (critical engagement with text) (Josselson, 2004; Ricoeur, 1970). Researchers working within the first position 'assume that the participant is an expert in his or her own experience and is willing and able to share meanings with the researcher' (Josselson, 2004: 5). For researchers working in the second position 'experience is assumed not to be transparent to itself' (Josselson, 2004: 5). These two approaches emanate from different epistemological positions and they lead to different readings. However, according to Ricoeur a dialectic between the two is possible, as the concepts of disguise-reveal and conceal-show are not external to each other but 'express two sides of a single symbolic function' (Ricoeur, 1970: 497, quoted in Josselson, 2004: 21). This view is supported by Jonathan Smith, who developed the IPA approach to qualitative research (e.g. Smith, 1996). Smith believes that both modes of hermeneutic engagement can contribute to a more complete understanding of the participant's lived experience. However "within such an analysis the empathic reading is likely to come first and may then be qualified by a more critical and speculative reflection' (Smith, 2004: 46).

As further examples of the focus on the researcher's role, the first issue of the new journal, Subjectivity, considers problems with notions of subjectivity in psychoanalytic psychosocial research that critiques post-structuralist discourse analysis and re-inscribes interiority (Wetherell, 2008). Recognition of the role that qualitative research can play in 'repopulating psychology' by emphasizing the relationship between the researcher and researched has contributed to the increasing prominence of qualitative research used in conjunction with quantitative approaches in research to support policy making and clinical practice (Todd et al., 2004). 
The expectation, however, that research findings, however obtained, will be presented to funders and journal editors in styles based on traditional quantitative reports means that qualitative research has largely implicitly adhered to positivist epistemology (Alvesson and Skoldberg, 2002). Data becomes regarded as facts, and 'findings' within it are presented as results of careful systematic categorization of details of the accounts provided by participants. There is little room for inclusion of consideration of researcher or method impact. Subjectivity or personal impact in quantitative research is regarded as a variable to be controlled (Drapeau, 2002) and this raises questions about the appropriateness of presenting qualitative research in written 'report' style presentations.

In this study we also found questions raised by the RAs about how to present their role in the analysis process. Some described their decisions to remove first person references while others simply used the third person throughout thereby disregarding the issue of explicit description of their role in the interpretative process. An effect of these decisions is to present the analysis under a guise of objectivity and the analyst as distanced from the narrator. The treatment of the interviewee's words as facts leaves little room for the illumination of the interpretative process. It is the terminology that is often associated with positivist-orientated approaches to conducting social research. Strikingly, and in contrast to the written presentation of their findings, all the RAs demonstrated awareness of the impact of their presence in the process when talking about the analysis process in their interviews.

New ways of presenting qualitative research and personal experience are beginning to emerge in the social sciences. They include performance work to present research on the self and identity through narrative analysis (Harbison, 2007), performative work on the maternal by artists such as Lena Simic (2008) and an increase in autobiographical writing about the experience of motherhood (e.g. Cusk, 2001).

The implicitly positivist approach inherent in the traditional style of presentation also serves to reduce and simplify the data, at the cost of its nuances and ambiguity. This might be explained in part by considering the structure of each method. IPA and grounded theory present semi-structured approaches to analysis which encourage narrative description after themes and categories have been identified in the data. The narrative and discourse analysis approaches employed in this study did not draw on particular models but more on the RA's choices and decisions. The RA interviews suggested that personal biography influences the choice of method to some degree with those who prefer organized thinking employing more structured methods and attempting to present the data into organized categories. This approach may perpetuate into the RA view of the data whereby those descriptions of experience that do not fit neatly are regarded as troublesome and 'messy'.

In their interviews, however, the RAs described becoming increasingly immersed in the data as they progressed through the analysis process. They 
began to ascribe characteristics to the narrator and to construct a world for her during the course of the analysis and subsequently spoke of the enjoyment and challenges of understanding her world. This gradual immersion and enjoyment of the process contrasted with their descriptions of beginning the analysis feeling bored and burdened by the work ahead of them.

The RAs spoke of their anxiety in carrying out the analysis and they described their concern about missing information in the data with their chosen method. It was also felt that no single method was sufficient to access all that the data may offer. The RAs had all been given minimal instructions in an effort to reduce the likelihood of the introduction of further overt subjectivity from the project co-ordinators. This may have contributed to confusion about what was expected of them. However the variation in the ways in which the RAs presented the analysis on paper also seemed to reflect the level of experience they had. Those with more experience of qualitative research used more tentative language than those with relatively less experience who had a more authoritative voice in their written accounts. The degree of experience in a particular approach to analysis has been highlighted as one that contributes to the prioritization in presentation of the findings of one method over another in mixed-method research (Bryman, 2007) and should perhaps be considered when assessing and teaching research conducted by students.

Findings in this study imply that the language currently available to describe and work with RA impact does not seem to provide a broad enough scope for its inclusion. As one participant at a PQR symposium put it 'The amount of hand waving when talking about subjectivity seems to suggest a difficulty in talking about it'.

The PQR project represents a start in the investigation of the pluralistic use of qualitative techniques, and how these can contribute to the debate about validity in qualitative research. This article provides a broad description of some of the emerging findings. The intention of the PQR team is to follow it with papers that provide further detail on issues such as polyvocality and the 'rhetorical turn' in relation to a pluralistic approach. The project did not allow for the interactive relationship that develops between a researcher-interviewer and interviewee and this is an important next step in the consideration of the role of the researcher in the research process. Further investigation of this would open the way for exploration of reflexivity in pluralistic qualitative research.

Using more than one qualitative technique has enabled greater understanding of the impact of researcher's biography, experience and their application of technique. Effects of methodological structure and presentation expectations are also illuminated. At a most basic level pluralistic use of qualitative approaches to analysis can be seen to raise awareness of the many points of impact that RAs have on their work. With further investigation of the creative tensions and potential benefits that combining qualitative methods give rise to we may be able to develop this approach as a useful way of informing not only the knowledge we gain as researchers but also the ways in which we seek to 
gain it. This approach might be seen to enhance the applicability and transparency of qualitative research. It may be that the next step in this process for social science researchers is to ask once again what kind of knowledge we wish to gain and for what purpose.

ACKNOWLEDGEMENT

The PQR project is an ongoing piece of live research. Its membership has grown from an original team of eight (Dr Nollaig Frost; Middlesex University, Dr Belinda Brooks-Gordon, Birkbeck, University of London; Dr Sevasti-Melissa Nolas, Middlesex University; Polona Curk, Cigdem Esin, Amanda Holt, Leila Mehdizadeh, Pnina Shinebourne) to a network of nearly 100 researchers following two collaborative symposia on the subject. We would like to thank all these people for their contributions to the work of the project so far.

\section{REFERENCES}

Alvesson, M. and Skoldberg, K. (2002) Reflexive Methodology. London: Sage.

Bruner, J. (1987) 'Life as Narrative', Social Research 34(1): 11-34.

Bryman, A. (2007) 'Barriers to Integrating Quantitative and Qualitative Research', Journal of Mixed Methods Research 1(1): 8-22.

Charmaz, K. and Henwood, R. (2008) 'Grounded Theory', in C. Willig and W. StaintonRogers (eds) (2008) The Sage Handbook of Qualitative Research in Psychology. London: Sage.

Clarke, A.E. (2003) 'Situational Analyses: Grounded Theory Mapping after the Postmodern Turn', Symbolic Interaction 26: 553-76.

Clarke, A.E. (2005) Situational Analyses: Grounded Theory after the Postmodern Turn. Thousand Oaks, CA: Sage.

Cortazzi, M. (2002[1993]) Narrative Analysis. Falmer Social Research and Educational Studies Series: 12. London: Falmer Press/Routledge.

Cusk, R. (2001) A Life's Work: On Becoming a Mother. London: Fourth Estate.

Denzin, N.K. and Lincoln, Y.S. (2000) Handbook of Qualitative Research. Thousand Oaks, CA: Sage.

Dicks, B., Soyinka, B. and Coffey, A. (2006) 'Multimodal Ethnography', Qualitative Research 6(1): 77-96.

Drapeau, M. (2002) 'Subjectivity in Research: Why Not? But....', The Qualitative Report 7(3), URL: http://www.nova.edu/ssss/QR/QR7-3/drapeau.html

Easterby-Smith, M., Golden-Biddle, K. and Locke, K. (2008) 'Working with Pluralism: Determining Quality in Qualitative Research', Organizational Research Methods 11: 419-29.

Eatough, V. and Smith, J.A. (2008) 'Interpretative Phenomenological Analysis', in C. Willig and W. Stainton-Rogers (eds) (2008) The Sage Handbook of Qualitative Research in Psychology, pp. 179-94. London: Sage.

Emerson, P. and Frosh, S. (2004) Critical Narrative Analysis in Psychology: A Guide to Practice. London: Palgrave.

Frosh, S. (2005) Hate and the 'Jewish Science': Anti-Semitism, Nazism and Psychoanalysis. Basingstoke and New York: Palgrave Macmillan.

Frosh, S. and Saville Young, L. (2008) 'Psychoanalytic Approaches to Qualitative Psychology', in C. Willig and W. Stainton-Rogers (eds) (2008) The Sage Handbook of Qualitative Research in Psychology. London: Sage. 
Frost, N.A. (2006) 'Taking the Other Out of Mother: The Transition to Second-Time Motherhood', Unpublished thesis, Birkbeck, University of London.

Frost, N.A. (2009) 'Do You Know What I Mean? The Use of a Pluralistic Narrative Analysis in the Interpretation of an Interview', Qualitative Research 9(1): 9-29.

Gee, J. (1991) 'A Linguistic Approach to Narrative', Journal of Narrative and Life History 1(1): 15-39.

Gill, R. (2000) 'Discourse Analysis', in M.W. Bauer and G.D. Gaskell (eds) Qualitative Researching with Text, Image and Sound: A Practical Handbook, pp. 172-90. London: Sage.

Glaser, B.G. (1978) Theoretical Sensitivity. Mill Valley, CA: Sociology Press.

Glaser, B.G. and Strauss, A.L. (1965) Awareness of Dying. Chicago: Aldine.

Glaser, B.G. and Strauss, A.L. (1967) The Discovery of Grounded Theory. Chicago: Aldine.

Halliday, M.A.K. (1973) Explorations in the Functions of Language. London: Edward Arnold.

Harbison, N. (2007) 'Doing Narrative Analysis', in E. Lyons and A. Coyle Analysing Qualitative Data in Psychology, pp. 145-57. London: Sage.

Howard, G.S. (1983) 'Toward Methodological Pluralism', Journal of Counseling Psychology 30(1): 19-21.

Hurwitz, B., Greenhalgh, T. and Skultns, V. (eds) (2004) Narrative Research in Health and Illness. Oxford: Blackwell.

Hydén, L.C. and Brockmeier, J. (eds) (2008) Health, Illness and Culture: Broken Narratives. London: Routledge.

Josselson, R. (2004) 'The Hermeneutics of Faith and the Hermeneutics of Suspicion', Narrative Inquiry 14(1): 1-29.

Kincheloe, J. (2001) 'Describing the Bricolage: Conceptualising a New Rigor in Qualitative Research', Qualitative Inquiry 7(6): 679-92.

Labov, W. (1972) Language in the Inner City: Studies in the Black English Vernacular. Philadelphia, PA: University of Pennsylvania Press.

Labov, W. and Waletzky, J. (1967) 'Narrative Analysis: Oral Versions of Personal Experience', in J. Helms (ed.) Essays on the Verbal and Visual Arts, pp. 12-44. Seattle, WA: American Ethnological Society/University of Washington Press.

Mason, J. (2006) 'Mixing Methods in a Qualitatively Driven Way', Qualitative Research 6(1): 9-25.

Mishler, E.G. (1986) Research Interviewing: Context and Narrative. Harvard, MD: Harvard University Press.

Moran-Ellis, J., Alexander, V.D., Cronin, A., Dickinson, M., Fielding, J., Sleney, J. and Thomas, H. (2006) 'Triangulation and Integration: Processes, Claims and Implications', Qualitative Research 6(1): 45-59.

Onwuegbuzie, A.J. and Leech, N.L. (2005) 'On Becoming a Pragmatic Researcher: The Importance of Combining Quantitative and Qualitative Research Methodologies', International Journal of Social Research Methodology 8(5): 375-87.

Parker, I. (1992) Discourse Dynamics: Critical Analysis for Social and Individual Psychology. London: Routledge.

Polkinghorne, D. (1988) Narrative Knowing and the Human Sciences. Albany, NY: State University of New York Press

Reason, P. and Riley, S. (2008) 'Co-operative Inquiry: An Action Research Practice', in J.A. Smith (ed.) (2008) Qualitative Psychology: A Practical Guide to Research Methods (2nd Edition). London: Sage.

Ricoeur, P. (1970) Freud and Philosophy: An Essay on Interpretation. New Haven, CT: Yale University Press.

Riessman, C.K. (1993) Narrative Analysis. Thousand Oaks, CA: Sage. 
Riessman, C.K (2003) 'Performing Identities in Illness Narrative: Masculinity and Multiple Sclerosis', Qualitative Research 3(1): 5-33.

Riessman, C. (2008) Narrative Methods for the Human Sciences. Thousand Oaks, CA: Sage. Sands, R.G. (2004) 'Narrative Analysis: A Feminist Approach', in D.K. Padgett (ed.) The Qualitative Research Experience. Toronto: Thomson.

Sarbin, T.R. (1986) Narrative Psychology: The Storied Nature of Human Conduct. New York: Praeger.

Schwandt, T.A. (2000) 'Three Epistemological Stances for Qualitative Inquiry: Interpretivism, Hermeneutics and Social Constructionism', in N.K. Denzin and Y.S. Lincoln (eds) Handbook of Qualitative Research, pp. 189-213. London: Sage.

Simic, L. (2008) URL: http://www.lenasimic.org

Smith, J.A. (1996) 'Beyond the Divide between Cognition and Discourse: Using Interpretative Phenomenological Analysis in Health Psychology', Psychology and Health 11: 261-71.

Smith, J.A. (2004) 'Reflecting on the Development of Interpretative Phenomenological Analysis and its Contribution to Qualitative Research in Psychology', Qualitative Research in Psychology 1: 39-54.

Stenner, P. (1993) 'Discoursing Jealousy', in E. Burman and I. Parker (eds) Discourse Analytic Research, pp. 114-34). London: Routledge.

Strauss, A. (1987) Qualitative Analysis for Social Scientists. New York: Cambridge University Press.

Todd, Z., Nerlich, B., McKeown, S. and Clarke, D. (eds) (2004) Mixing Methods in Psychology. New York: Psychology Press.

Venn, C. (1998) 'The Subject of Psychology', in J. Henriques, W. Hollway, C. Urwin, C. Venn and V. Walkerdine (eds) (1998) Changing the Subject: Psychology, Social Regulation and Subjectivity. London: Methuen.

Walton, C. (2007) 'Doing Discourse Analysis', in E. Lyons and A. Coyle (eds) Analysing Qualitative Data in Psychology, pp. 117-30. London: Sage.

Wetherell, M. (2008) 'Subjectivity or Psycho-discursive Practices? Investigating Complex Intersectional Identities', Subjectivity 22: 73-81.

Willig, C. (2001) Introducing Qualitative Research in Psychology: Adventures in Theory and Method. Buckingham: Open University Press.

Willig, C. (2008) Introducing Qualitative Methods in Psychology (2nd Edition). Buckingham: Open University Press.

Willig, C. and Stainton-Rogers, W. (eds) (2008) The Sage Handbook of Qualitative Research in Psychology. London: Sage.

Wood, L. and Kroger, R. (2000) Doing Discourse Analysis. London: Sage.

NOLLAIG FROST (Senior Lecturer, Middlesex), BELINDA BROOKS-GORDON (Reader, Birkbeck), SEVASTI-MELISSA NOLAS (Lecturer, Middlesex University) and PNINA SHINEBOURNE (Lecturer, New School of Psychotherapy and Counselling) were all in the Centre for Psychosocial Studies, School of Psychology, Birkbeck, on the PQR project team. CIGDEM ESIN (PhD student, University of East London), AMANDA HOLT (Senior Lecturer, University of Portsmouth) and LEILA MEHDIZADEH (PhD student, University of Leeds) were working from University of East London, University of Brighton and University of Leeds on the PQR team. Address: Department of Psychology, School of Health and Social Services, Middlesex University, The Burroughs, London NW4 4BT, UK. [email: n.frost@mdx.ac.uk] 